\title{
Why Incremental Reforms Will Not Solve the Health Care Crisis
}

Don McCanne, MD

The need for major health care reform in the United States is not disputed. Increasing financial barriers to care have impaired health care coverage and access and have resulted in impaired health outcomes for the ever-increasing numbers of Americans who are victims of our unique system that rations care by the ability to pay. ${ }^{1}$ The status quo is not acceptable.

The Clinton administration's effort to enact comprehensive reform was such a spectacular failure that most reform advocates decided that a single step to universal coverage was not politically feasible. Since then, almost all policy strategists agree that reform must occur in incremental steps, ultimately culminating in universal or near-universal coverage. Any model that expanded existing programs or added new programs could be considered, but comprehensive programs that replaced the current mechanisms of funding care, such as single payer or health service models, were automatically excluded from the national debate on reform. $^{2}$

As our mechanisms of funding care deteriorate further, we should readdress the issue of whether the discussion of reform should be limited to incremental proposals. An assessment of incremental measures of the past decade and of proposals for the near future can be instructive.

\section{How Effective Has Incrementalism Been?}

The record of incrementalism to date is unimpressive. Medicaid, the State Children's Health Insurance Program, and the Health Insurance Portability and Accountability Act have been important programs that have provided access and coverage for many who need it. These programs alone, how-

Submitted, revised, 6 February 2002.

From Physicians for a National Health Program, Chicago, Ill. Address reprint requests to Don R. McCanne, MD, 33781 Avenida Calita, San Juan Capistrano, CA 926754905 . ever, have been grossly deficient in filling the greater voids in our system. The numbers of uninsured Americans continue to increase. Health care costs continue to escalate well beyond the rate of inflation, while no efforts are being made to reduce the egregious waste of our administrative excesses. We are spending more on health care administration alone than is allocated for our entire national military defense budget. ${ }^{3}$ Health care outcomes continue to be much worse in the United States than in other industrialized nations that provide coverage for everyone at a much lower cost than that of our fragmented and inefficient system. ${ }^{4}$ Furthermore, inadequate coverage is now threatening the financial security of many of those that actually do have insurance.

Despite the failure of incrementalism, these approaches continue to have support primarily because of the perception that the nation does not want a "taxpayer-funded, government solution." Ironically, health care is already 60\% publicly funded, and nearly all incremental proposals involve public policy, especially tax policy, and actually further increase taxpayer funding of health care. ${ }^{6}$ Let us look at some of the existing programs and innovative proposals.

\section{Medicaid and the State Children's Health Insurance Program (SCHIP)}

As noted, Medicaid and SCHIP are important programs that have provided coverage for low-income children and some adults and have been effective in improving health care outcomes for these underserved population groups. Chronic underfunding of both programs, however, has resulted in financial burdens for the individual and institutional health care providers that are attempting to provide services within these constraints. Underfunding has also resulted in shifting cost to other payers of health care. An even greater concern is that, because of the financial and administrative burdens, 
many providers refuse to participate in these programs, thus impairing access to those with the greatest needs. In fact, with the ratcheting down of reimbursement rates by health plans and by other government programs, some providers are not able to maintain an adequate income if they participate in these programs.

Perhaps the greatest problem with Medicaid and SCHIP is that they are designed specifically for low-income populations, an element with an insignificant political voice. During the appropriations process, these population subsets are considered to be "welfare recipients," and legislators have no motivation to fund these programs adequately. Relying on public programs limited to low-income groups can only perpetuate inequities and impair access for these less fortunate persons.

\section{Tax Credits}

About $80 \%$ of uninsured Americans are employed, but their employers often do not offer affordable health plans, and their incomes are insufficient to purchase coverage in the individual health insurance market. ${ }^{7}$ To make insurance affordable, tax credits have been proposed that would be applied toward the purchase of private health plans. The credits would be progressive, with larger credits being directed to lower income wage earners, and they would be refundable, so that those with very low incomes who pay little or nothing in income taxes would still receive the credit. The logic of this approach makes it seem like an ideal answer if we were to continue to insist that reform must be incremental. A closer look reveals severe deficiencies, however.

Health plans in the individual market are no bargain when compared with group plans. The costs of individual coverage are about $30 \%$ higher than group plans. This amount alone would consume the tax credit for many recipients. Furthermore, individual plans frequently have sparse benefits and considerably higher out-of-pocket expenses, threatening the affordability of care for those with serious acute or chronic problems, even if they are insured. Worse, underwriting practices in the individual market allow the plans to deny coverage to those who do have or might be anticipated to have major health care expenses. As a result, the individual market insures low-cost, healthy persons but abandons precisely those that have the greatest needs for health care coverage.
Another defect of tax credits is that they do not work. Jonathan Gruber, at the Massachusetts Institute of Technology, has analyzed the impact of the Bush tax credit proposal (Gruber J. Testimony before the House Ways and Means Committee, Subcommittee on Health, Hearing on Health Insurance Credits, February 13, 2002). President Bush proposes a progressive, refundable $\$ 1,000$ credit for individuals and $\$ 3,000$ for families. Although the take-up rate would be considerable, Gruber showed that employers would reduce coverage. The net reduction in the numbers of uninsured would be less than 2 million, only $5 \%$ of the currently uninsured. He also showed that increasing the amount of the credit would dramatically increase the public (tax) cost while having little further impact on the numbers of the uninsured, because most participants would be shifted from the group already insured. Considering the excessive administrative waste inherent in the private health plans, this use of public funds would be inappropriate.

\section{Medical Savings Accounts}

Medical savings accounts (MSAs) are individual savings accounts that accumulate tax-free but can be used only for medical expenses without incurring taxes and penalties. They are backed up by high-deductible, catastrophic insurance coverage. A common perception of MSAs is that all up-front health care expenses will be paid from these accounts with no limits on fees and no restrictions on services, and that $100 \%$ of the balances will be covered by a low-cost, catastrophic, indemnity-type plan. In fact, the high-deductible insurer is usually a managed care preferred-provider organization (PPO) or even a more restrictive exclusive provider organization (EPO). Additionally, if the insurer is not allowed the option of excluding higher cost individuals during an underwriting process, then the coverage cannot possibly be low cost. Because of the problems with MSAs, the insurance industry is responding with their own version of segregated beneficiary accounts: health spending accounts.

\section{Health Spending Accounts}

Employers and the insurance industry have established MSA look-alike models, known as health spending accounts (HSA), consumer-driven health plans, personal health accounts, and other labels. A 
recent Internal Revenue Service ruling has engendered support for this innovation. Called health reimbursement arrangements (HRAs) by the IRS, the funds in this version of these accounts now can be rolled over from year to year. The nation's largest purchaser of health plans, the Federal Employees Health Benefits Program (FEHBP), announced the introduction of HSAs as a new consumer-directed option available next year. Blue Cross of California also recently announced the introduction of the Power HealthFund PPO, a consumer-driven health plan. Many other insurers are rolling out their own versions. Other versions exist, such as flexible spending accounts, and although the specifics of these segregated beneficiary accounts might vary, the fundamental concept is the same for all of them.

With the insurance versions of HSAs, the insurance industry can continue to collect administrative fees without being exposed to any risk, because the funds in the accounts belong to the beneficiaries or, in some versions, to the employer. Once the individual account is depleted, the beneficiary is responsible for the full deductible before the catastrophic coverage begins. Until that point, the insurer has assumed no risk. Because the catastrophic coverage is a managed care plan, usually a $\mathrm{PPO}$, the insurer reduces its risk by locking the providers into contracts with restricted fees, restricted benefits, and restricted provider lists. The beneficiary, who has received no tangible benefit to this point, could even be required to participate in cost sharing in the high-deductible coverage. HSAs shift much of the risk and costs from the insurer to the beneficiary.

\section{Defined Contribution Proposals}

Rather than funding the costs of health care plans, defined contribution proposals define the amount of funds that will be contributed toward payment of the premium. Where the individual participant has a choice of plans, his or her contribution to the premium depends on the richness of the benefit package and the amount of cost sharing that the plan provides. Theoretically, the participant reduces costs by choosing only the amount of coverage needed, as if anyone were capable of predicting that. In reality, it is merely a method of shifting the rising costs of health care to the participant. Some employers have already adopted this approach, and it is being recommended seriously for our Medicare program in the form of the Breaux-Frist "premium support" proposal. It can only result in an increase in the numbers of uninsured and underinsured as health care premiums and cost sharing become less affordable.

\section{Employer Mandate}

Employer mandate requires that each employer provide coverage for every employee. Employer mandates leave in place our administratively burdensome, inefficient, and inequitable method of funding health care. Many smaller employers and those who are self-employed simply cannot afford to purchase health plans. Employer mandates would require administratively complex mechanisms that assist with funding the plans. In addition, other programs would be required to cover those who are unemployed and others who would not fall within the mandate. Inevitably, many Americans would still remain without coverage. Because of the failure to capture costs related to administrative inefficiencies, employer mandates would not control costs, but would continue to waste resources.

\section{Individual Mandate}

Mandating individual Americans to purchase their own health insurance would be even less effective than existing auto insurance mandates, especially considering the higher costs of health insurance. Penalizing those without adequate disposable income for not having health insurance after the need arises cannot ever be an effective public policy to assure adequate coverage for everyone. Requiring someone to have funds that he or she does not have simply will not work. Tax credits, as we have seen, will not provide an adequate answer.

\section{Consumer-Driven Plans and Cost Containment}

Consumer-driven health care plans are promoted as a method of eliminating wasteful spending in health care by making the patient sensitive to the costs of care. These plans, including health spending accounts, require patients to contribute their own funds toward services that are actually rendered. The theory is that health care costs would be reduced because patients would not want to pay for services they do not really need. In reality, cost 
sharing erects financial barriers to beneficial services and might have a greater negative impact than the benefit of a modest reduction in superfluous services.

Because of the increase in cost sharing and the need to pay for services that are not a benefit of the plan, patients with either severe acute or chronic disorders who have an increased need for health care services might find health care to be unaffordable even though they have health care coverage. Medical bills are already a major cause of personal bankruptcy for Americans, including many who have coverage, but their coverage fails to eliminate substantial financial exposure. ${ }^{8}$ With the increase in consumer-driven insurance products, we can anticipate even more personal bankruptcies as a result of medical bills.

Do healthy persons have any cause for concern? After all, they can select the low-premium plans and hope that they will not develop problems that might expose them to major expenses. Most will win this bet and end up better off financially. Those who lose will understand why we need comprehensive coverage for everyone. Once personal reserves are depleted, the sharing of further health care costs can be unaffordable. Accordingly, these plans offer neither assured financial security nor assured health security.

What about those who have a comfortable income? They can pay the higher premiums for more comprehensive coverage. Those persons who anticipate high expenses because of preexisting, chronic disorders, however, will have to buy the more comprehensive plans to avoid the high outof-pocket expenses. Plans that concentrate highcost patients will be forced to increase their premiums dramatically. Eventually the premiums become unaffordable, and the plan loses market share and is forced to withdraw from the market. This outcome is referred to as the death spiral of health plan premiums. Although the very wealthy will not be concerned about the lack of comprehensive plans, average-income persons, the majority of us, should be alarmed at this prospect. The primary purpose of health insurance, providing financial security in the event of loss, is being abandoned by the industry.

Would the very wealthy have any concerns? If those of average income cannot pay for major disorders, if public programs are underfunded, if employers shift more costs to employees through de- fined contribution proposals, and if insurers continue to slash their share of payments for services, what will happen as a result of this underfunding of the health care delivery system? We already know the answer, because the transition of our system has begun to take place. Trauma centers are closing down. Those in need of immediate medical care who must bypass a shuttered trauma center as they are transferred across town will die no matter how much money they have. ${ }^{9}$ We can anticipate further deterioration of the health care infrastructure as funds continue to be diverted away from the institutions and those who provide care.

\section{The California Health Care Options Project}

The California Health and Human Services Agency recently coordinated a study of nine different models of health care reform prepared by various persons and organizations, including health policy professors from the University of California campuses at San Francisco, Berkeley, Los Angeles, and San Diego. ${ }^{10}$ Each model was subjected to an independent microsimulation. The three proposals that were comprehensive included two single payer models and a health service model. The study showed that these three models would provide comprehensive coverage for everyone, and all three were projected to save Californians billions of dollars in health care costs. The other six proposals were expansions of our current system and could be described as incremental models. All six fell short on reform goals, leaving in place many of our current flawed policies, and all them were projected to increase health care costs for Californians. One model, a combination of an employer mandate and a single public program for all others, came close to meeting some of the goals, but it was also the most expensive proposal.

\section{Conclusion}

Incremental models of reform perpetuate our flawed, fragmented system of funding health care. They perpetuate inequities both in the funding of health care and in the allocation of our health care resources. They limit choice of health care providers. None assures continuity of coverage and care. Many incremental proposals barely have an effect on the numbers of uninsured, and none of them ensure truly universal coverage. All incremental approaches substantially increase health care costs, 
and most current proposals assure neither financial security nor health security.

In contrast, a single payer program would provide affordable, equitable, comprehensive care for everyone.

Whether through tax policy, public programs, regulatory oversight, mandated coverage, or a combination of these and other interventions, the government will be intimately involved in our health care funding. We can no longer afford to dismiss any valid option because it is a government solution, especially in that all proposals are government solutions. We must decide how we can best use our government resources to be sure that we are receiving the greatest value for our health care investment. Limiting our consideration to various incremental solutions closes the door on the health care reform goals of equity, affordability, and efficiency, and it threatens the goals of universality, provider choice, access, and comprehensiveness. When all are readily achievable, why accept less?

\section{References}

1. Reinhardt U. Dividing up health care by income class. Boston Globe August 19, 2002.
2. Donohue T. Covering the uninsured - strengthening employer-based coverage? Available at: www. pnhp.org/news/archives/001224.php. Accessed November, 2002.

3. Woolhandler S, Himmelstein DU. The deteriorating administrative efficiency of the U.S. health care system. N Engl J Med 1991;324:1253-8.

4. Musgrove $\mathrm{P}$, Creese A, Preker A, et al. The world health report 2000: health systems: improving performance. Geneva: World Health Organization, 2000.

5. Blendon RJ. Voter concern is down. USA Today November 7, 2002.

6. Woolhandler S, Himmelstein DU. Paying for national health insurance-and not getting it. Health Aff (Millwood) 2002;21:88-98.

7. Budetti J, Duchon L, Schoen C, Shikles J. Can't afford to get sick: a reality for millions of working Americans: the Commonwealth Fund 1999 national survey of workers health insurance. (Report 347.) New York: The Commonwealth Fund, 1999.

8. Warren E, Sullivan T, Jacoby M. Medical problems and bankruptcy filings. Norton's Bankruptcy Adviser, May 2000.

9. Brewer S. Study: clogged trauma care leads to deaths. Houston Chronicle, November 21, 2002.

10. Health care options project. California Health and Human Services Agency, 2002. Available at: www. healthcareoptions.ca.gov/. Accessed November, 2002. 